\title{
An Assessment of the Health Communication Job Market across Multiple Types of Organizations
}

\author{
KAREN FOWLER \\ CARIN CELEBUSKI \\ TIMOTHY EDGAR
}

\author{
Westat \\ Rockville, Maryland, USA
}

FRED KROGER

Centers for Disease Control and Prevention

Atlanta, Georgia, USA

SCOTT C. RATZAN

Academy for Educational Development

Washington, DC, USA

\begin{abstract}
This study seeks to answer three questions: (1) What is the employment outlook for health communication practitioners? (2) What specialized knowledge and skills should a competent health communication practitioner possess? and (3) How much academic training or professional experience is necessary to become a competent health communication practitioner? To this end, 104 employers of health communication practitioners, representing different types of large, medium, and small companies and organizations from various regions of the United States, were interviewed by telephone. The interview protocol was based on nine core health communication responsibilities identified by a working group of health communication academicians and practitioners. The study suggests a positive employment outlook, where those seeking jobs in health communication before the year 2000 could enjoy varied job opportunities in the wake of an anticipated moderate expansion in the field. Those with 1 to 10 years of experience are most in demand. While an undergraduate degree provides an academic background to perform most responsibilities, for six of the nine core responsibilities an advanced degree was preferred by at least one-third of respondents.
\end{abstract}

Health communication is a relatively new area of research and practice that parallels several other new fields of study, including health psychology, medical sociology, biomedical communication, behavioral medicine, behavioral health, risk communication, and medical communication. These newer fields are building on the groundwork laid by professional disciplines such as nursing, social work, psychology, sociology, medicine, and public health. Health communication can be viewed as interdisciplinary in nature, overlapping these other fields, while focusing more specifically on communication issues in health care settings (Northouse \& Northouse, 1985). Because of this interdisciplinary nature, only a few practitioners of health communication have actually studied in a health communication academic program. Several academic and professional efforts are ongoing to develop health communication as a discipline unto itself.

Address correspondence to Karen Fowler, MPH, Westat, 1650 Research Boulevard, Rockville, MD 20850, USA.

This project was funded by the Centers for Disease Control and Prevention contract 200-93-0653.

An earlier version of this article was selected as a top three paper by the International Communication Association, 1998. 
In the field of communication, efforts to develop health communication include the establishment of distinct health communication programs within schools of communication and university communication departments (Ratzan, Stearns, Payne, Amato, Liebergott, \& Madoff, 1994; Stearns, Ratzan, Hyde, Newell, Joyce, \& Freeman, 1996; Maibach, Parrott, Long, \& Salmon, 1994). Although this represents a relatively small number of colleges and universities in the United States, there are indications from other colleges and universities that health communication is evolving. For instance, the Health Communication Division of the National Communication Association lists on its web site at least 70 universities or schools of communication believed to have courses in health communication (HealthCOMM, 1999).

The field of public health has also taken steps to develop the field of health communication and to integrate health communication into public health practice. In 1992 the Centers for Disease Control and Prevention incorporated health communication into its prevention strategies, adding "Prevention" to its official title and shortly thereafter establishing an Office of Communication (Roper, 1993). Furthermore, the theme of the American Public Health Association's 1997 annual meeting and exposition was "Communicating Public Health." In the academic arena, a perusal of the web sites of 22 of the 28 accredited schools of public health finds that health communication courses have been integrated into health education, community health, or behavioral health science curricula. The Association of Schools of Public Health web site lists 15 public health schools offering a major area of study in communication theory or health media (Association of Schools of Public Health, 1999). In order to develop a program of training as part of a Masters in Public Health, a working group of expert health communication academics and practitioners was convened in October 1992 to define the core responsibilities that compose the practice of health communication (Maibach et al., 1994).

The skills of health communication practitioners have not been well characterized for this emerging professional discipline. Curricula for aspiring practitioners are just now being advanced. Codifying the core responsibilities expected of practitioners, in an environment of rapidly changing technologies, health care delivery systems, and opportunities, would be a landmark event in the evolution of public health practice. Such information is needed to guide important decisions on the part of academic institutions; public, private, and voluntary health agencies; and aspiring practitioners. To this end, we conducted research with those who employ and supervise health communication practitioners in order to answer three overarching questions: (1) What is the employment outlook for health communication practitioners? (2) What specialized knowledge and skills should a competent health communication practitioner possess? and (3) How much academic training or professional experience is necessary to become a competent health communication practitioner?

\section{Methods}

\section{Interview Instrument Development}

The primary tool used for data collection was a telephone interview of employers of health communication practitioners. To guide the development of the interview instrument and protocol, we initially conducted open-ended telephone interviews with 18 high-profile health communication practitioners and supervisors concerning

\section{Click here to access the Journal of Health Communication Online}


the responsibilities and skills of health communication practitioners and the outlook for employment. The 18 practitioners and supervisors represented all regions of the country and included representatives from a wide variety of organizations: academic, public health, health care, public relations and marketing, nonprofit, government, and professional membership associations. Researchers derived nine core health communication responsibilities from these interviews. To examine the usability of the resulting telephone interview instrument, we also conducted a pilot study with 18 additional health communication practitioners and supervisors. The final survey asked questions about the respondents' setting and the group of employees supervised by the respondents and focused on the nine health communication responsibilities (Table 1).

\section{Sample}

The study focused on individuals who supervised employees who (1) communicate about health to the public, patients, health care providers, or members of their organization, or (2) conduct research on or evaluate strategies to communicate about health to the public, patients, health care providers, or members of their

TABLE 1 Respondents Who Hire or Supervise Employees with Health Communication Responsibilities

\begin{tabular}{|c|c|c|c|}
\hline \multirow{2}{*}{$\begin{array}{c}\text { Nine Core Health Communication } \\
\text { Responsibilities }\end{array}$} & \multicolumn{2}{|c|}{$\begin{array}{c}\text { Hire or } \\
\text { Supervise } \\
\text { Employees } \\
\text { with } \\
\text { Responsibility }\end{array}$} & \multirow{2}{*}{$\begin{array}{c}\text { Perform } \\
\text { Responsibility } \\
\text { Themselves } \\
(\%)^{*}\end{array}$} \\
\hline & $N$ & $\% *$ & \\
\hline All respondents & 104 & 100 & - \\
\hline $\begin{array}{l}\text { Design programs, campaigns, or } \\
\text { materials }\end{array}$ & 97 & 93 & 81 \\
\hline $\begin{array}{l}\text { Evaluate programs, campaigns, } \\
\text { or materials }\end{array}$ & 68 & 65 & 76 \\
\hline $\begin{array}{l}\text { Teach classes or provide training } \\
\text { about health }\end{array}$ & 58 & 56 & 62 \\
\hline $\begin{array}{l}\text { Conduct research to develop programs, } \\
\text { campaigns, or materials }\end{array}$ & 57 & 55 & 68 \\
\hline $\begin{array}{l}\text { Market health-related products or } \\
\text { services }\end{array}$ & 56 & 54 & 70 \\
\hline Develop health-related public relations & 49 & 47 & 74 \\
\hline $\begin{array}{l}\text { Administer health information } \\
\text { consumer services }\end{array}$ & 46 & 44 & 48 \\
\hline $\begin{array}{l}\text { Organize coalitions or act as an } \\
\text { advocate }\end{array}$ & 38 & 36 & 76 \\
\hline $\begin{array}{l}\text { Obtain funding for communicating } \\
\text { about health }\end{array}$ & 31 & 30 & 84 \\
\hline
\end{tabular}

* Percentage of those who hire or supervise employees for a responsibility $(N)$. 
organization. Since there was not a frame from which to select a probability sample of employers of health communication practitioners, researchers relied on a quota sample. To obtain an acceptable number of responses from employers in a wide variety of settings, the research team set a goal of including at least 100 participants in the study. The system by which the quota sample was chosen began with the development of a sample matrix. Researchers identified four organization types that might potentially employ health communication practitioners: government agencies, health care industry, nonprofit organizations, and for-profit organizations (see Appendix A for details). These types formed the basis of the sample matrix and were then divided into four geographic regions (Northeast, Southeast, Central, and West) and by organization size (small, medium, and large) within geographic region. For each cell on the matrix, we assigned a target quota of respondents. The quotas were assigned so that respondents would be distributed approximately equally in terms of organization type, geographic distribution, and organization size. We then developed lists of potential respondents for each cell using the Dun \& Bradstreet business listing (by Standard Industrial Classification [SIC] code), a list of government agencies, and the HEP directory of institutions of higher education. Each eligible respondent was matched to a slot on the matrix. Interviewers called organizations on the list until the target quota of respondents for each slot was reached. About half of the organizations screened for the study were eligible (i.e., they had health communication practitioners on staff), and of those contacted and eligible, about half were able to participate. In all, there were 104 respondents.

\section{Data Collection Procedures}

Trained telephone interviewers contacted each selected organization's personnel department, informed them of the research objectives, and gained permission to interview an employee who met the study criteria. If the personnel office identified more than one individual, the interviewer asked for the person with the largest health communication staff. If the organization had an employee who met the criteria, the interviewer then contacted and screened that person. The screener asked the individual identified by the personnel office to confirm that he or she supervises or hires health communication practitioners. Once this was confirmed, the interviewer set up an appointment to administer the questionnaire.

Recruited respondents received a letter describing the study and what they could expect during the telephone interview, a printed list of the responsibilities to be asked about, and a printed list of skills (see Appendix B). The list of responsibilities was sent to give respondents an advance idea of the types of jobs we would ask about in the interview. The reference list of skills was sent because the instrument testing showed that respondents were more comfortable answering the skills questions using a list. Data collection began in October 1996 and was complete in January 1997. The interviews ranged from approximately 20 minutes to nearly an hour in length, depending on how many of the responsibilities the respondent supervised.

During the interview, respondents were asked 10 questions about each of the 9 core health communication responsibilities for which they hired or supervised employees. Respondents were also asked for their current job title, whether they specialized in a particular health content area, and what term they would use to describe their profession. Most of the responses on the questionnaire were precoded for ease of administration. There were several open-ended questions that were not 
precoded because of the variety of responses expected. Interviewers also recorded comments respondents made during the interviews.

\section{Data Preparation and Analysis}

Project staff reviewed the questionnaire and keyed the data into an electronic data file. Descriptive statistics were produced, including frequencies; cross-tabulations by size, region, and type of organization; and means of the continuous variables. In addition, analyses of variance were run for the continuous variables to check for statistically significant differences between means from different groups. Responses to open-ended questions were keyed verbatim into an electronic data file and were printed out. Like responses were grouped into substantively relevant categories. These grouped responses were analyzed and reported.

\section{Respondent Characteristics}

Most respondents held titles within their organizations such as director, manager, or vice president. Although many worked in departments dedicated to health or communication, the job title of only one respondent specifically referred to health communication. The job titles of other study respondents can be categorized into the following five groups: (1) health promotion, health education, health services; (2) communication, public information, public affairs; (3) sales and marketing; (4) personnel or human resources; and (5) general administration.

When asked to describe the health content area in which they specialize, respondents gave mostly the category of medical skills (e.g., nursing, critical care, emergency medicine, behavioral health care). Others responses were fairly evenly distributed among the categories of aging, chronic disease, health care industry, health communication or education, infectious disease, injury and safety, maternal and child health, and pharmaceuticals.

When asked what terms they would use to describe their profession, most respondents used health- or communication-related descriptors, such as "fitness," "health promotion," "marketing," and "public affairs," but only seven respondents used the term "health communication."

\section{Results}

\section{The Employment Outlook for Health Communication Practitioners}

Of the nine core responsibilities the one for which the most respondents hired or supervised staff was designing health communication programs (93\%; see Table 1). More than half of the respondents had staff who did program research, program evaluation, teaching or training, or health-related marketing. The fewest respondents had staff who obtained funding (30\%) and organized coalitions or acted as an advocate (36\%).

Respondents who supervise or hire staff who engaged in the responsibilities of interest also were asked how many staff members currently perform each responsibility. The results showed relatively little variation across responsibilities. The median number of staff for the nine responsibilities ranged from three to five.

Respondents who said they currently hire or supervise staff for a responsibility were asked if they expected their organization to need more, the same, or fewer

\section{Click here to access the Journal of Health Communication Online}




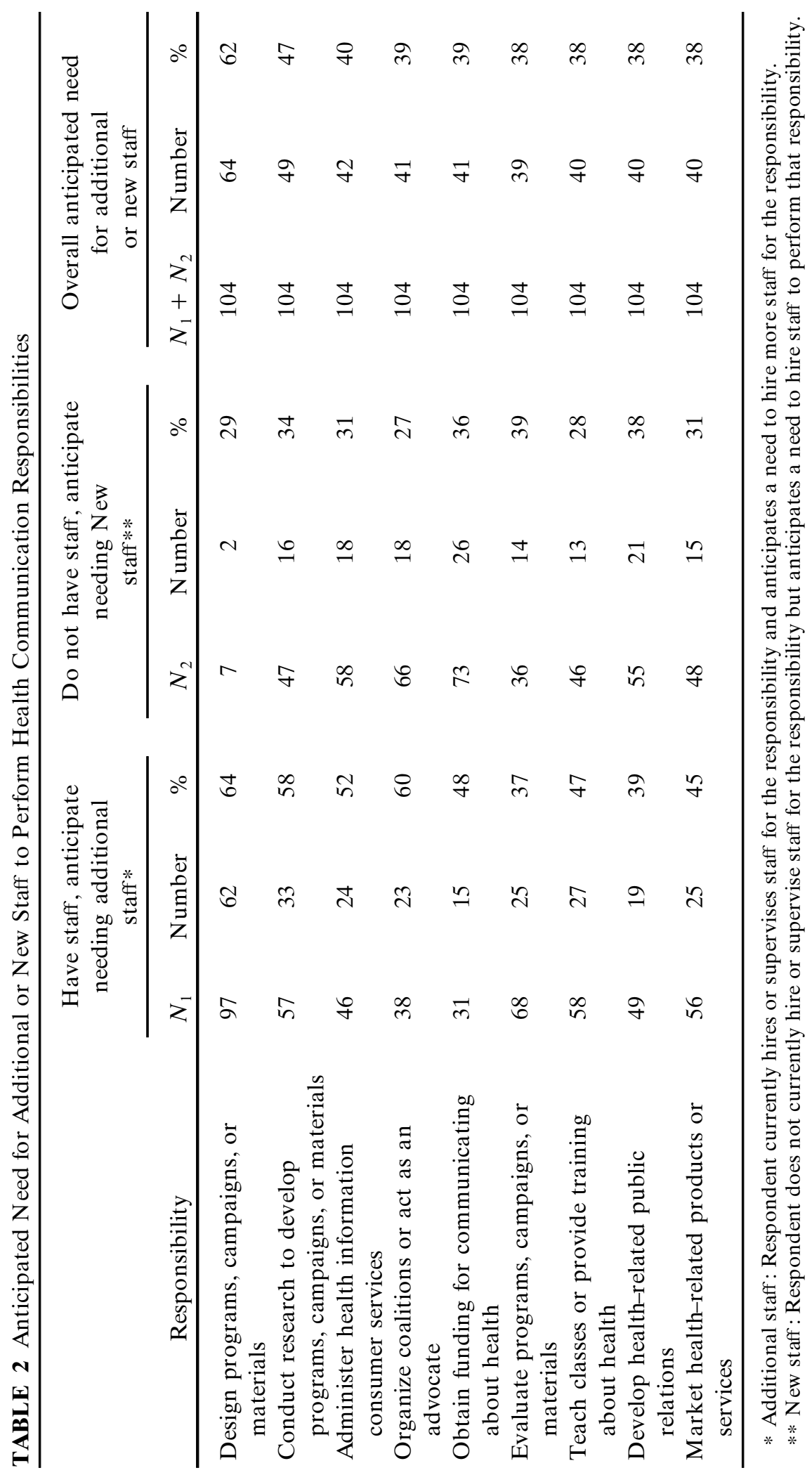


people to perform this responsibility in the next 1 to 3 years. Table 2 shows the greatest anticipated needs for additional staff were in program design (64\%) and organizing coalitions or acting as an advocate (60\%); the lowest anticipated need for additional staff was in program evaluation (37\%).

Those respondents who indicated that they did not currently have employees with a particular responsibility were asked if they anticipated that their organization would have a need for new hires to perform that role in the next 1 to 3 years. The percentage of respondents who said that their organization would probably need new staff ranged from $27 \%$ to $39 \%$ for the nine responsibilities.

Combining information from both need questions (need for additional staff and need for new staff) provides the most comprehensive view of future hiring and the most optimistic news. For example, for evaluation, we combined the 25 respondents who anticipated hiring additional staff with the 14 respondents who predicted their organization would need staff for this new responsibility. The resulting figure shows that $38 \%$ of the study sample expressed an overall need for either new or additional staff to take on evaluation responsibilities (Table 2). The results for all responsibilities were similar, with $38 \%$ to $40 \%$ of the respondents for seven of the nine responsibilities expressing a need for new or additional staff. The two exceptions were program design and program research, which showed anticipated needs of $62 \%$ and $47 \%$, respectively.

Cross-tabulations were run to investigate relationships between organizational characteristics and the need for health communication responsibilities. The organizations that composed our sample were stratified by geographic location, type of organization, and size of organization. In general, the cross-tabulations either revealed no observable difference or produced cell sizes too small for meaningful analysis.

\section{Knowledge and Skills a Competent Health Communication Practitioner Should Possess}

The study addressed two interrelated issues concerning respondents' expectations of the types of knowledge involved in health communication. Respondents were asked (1) to what degree specialized knowledge in a health content area would be important in order for staff to perform the health communication responsibility; and (2) if they perceived it to be important, what specific area it should be in. The term "specialized knowledge" meant that individuals would have experience, training, or education in a specific content area, such as AIDS, chronic disease, or other health problems.

For all responsibilities, at least $87 \%$ of the respondents ranked specialized knowledge as "somewhat important" or "very important" (Table 3). ${ }^{1}$ Responsibilities for which specialized knowledge in a health content area was reported as being very important rather than somewhat important were obtaining funding for communicating about health and teaching classes or providing training about health. Teaching classes or providing training was the responsibility with the most marked emphasis on the importance of specialized knowledge: $79 \%$ of respondents ranked it as very important.

${ }^{1}$ Note that because respondents typically did not hire or supervise for all nine responsibilities and the data collection protocol was to only gather data regarding those responsibilities for which the respondent hires or supervises, the number of total respondents will vary from responsibility to responsibility.

\section{Click here to access the Journal of Health Communication Online}




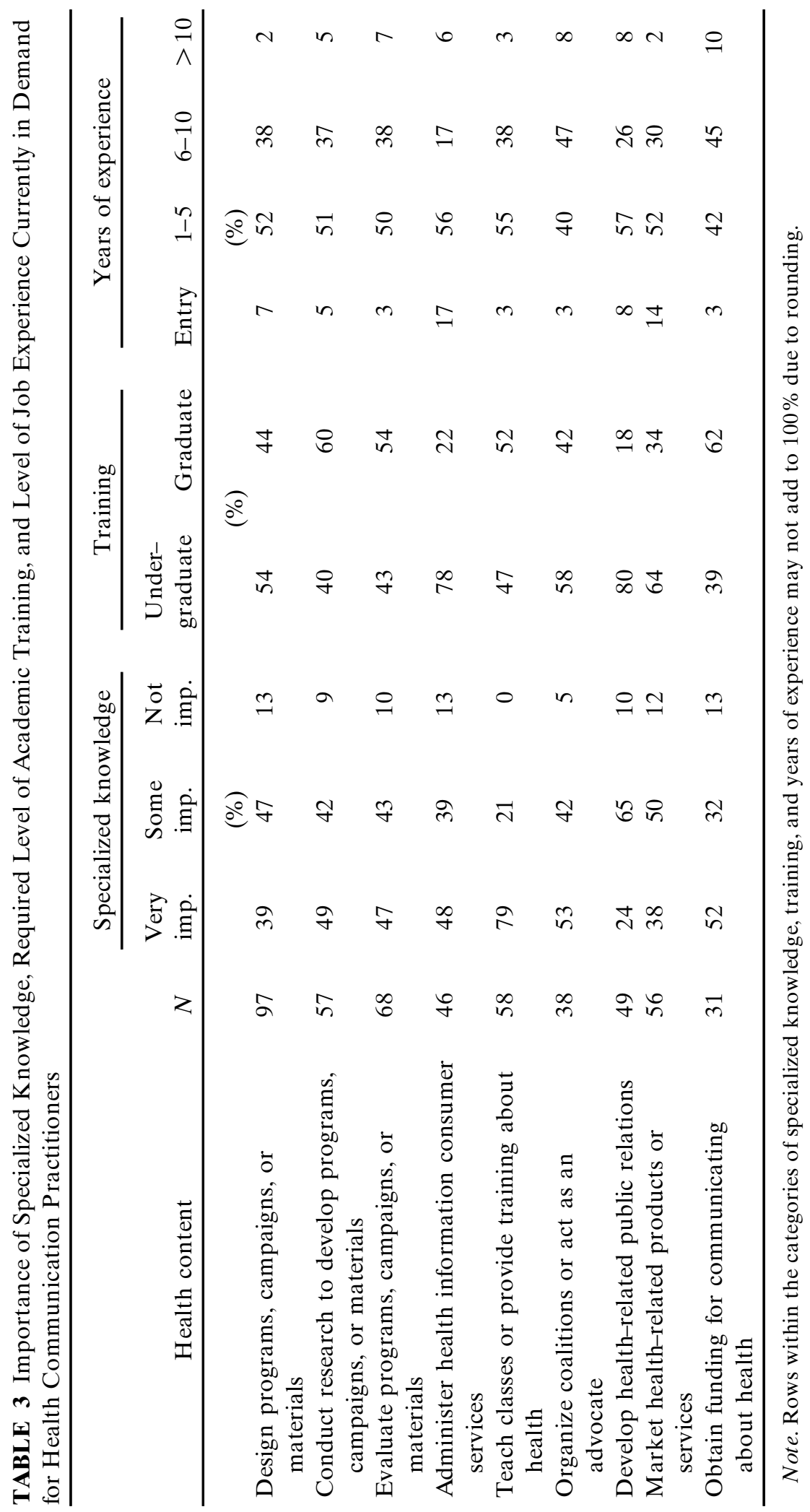




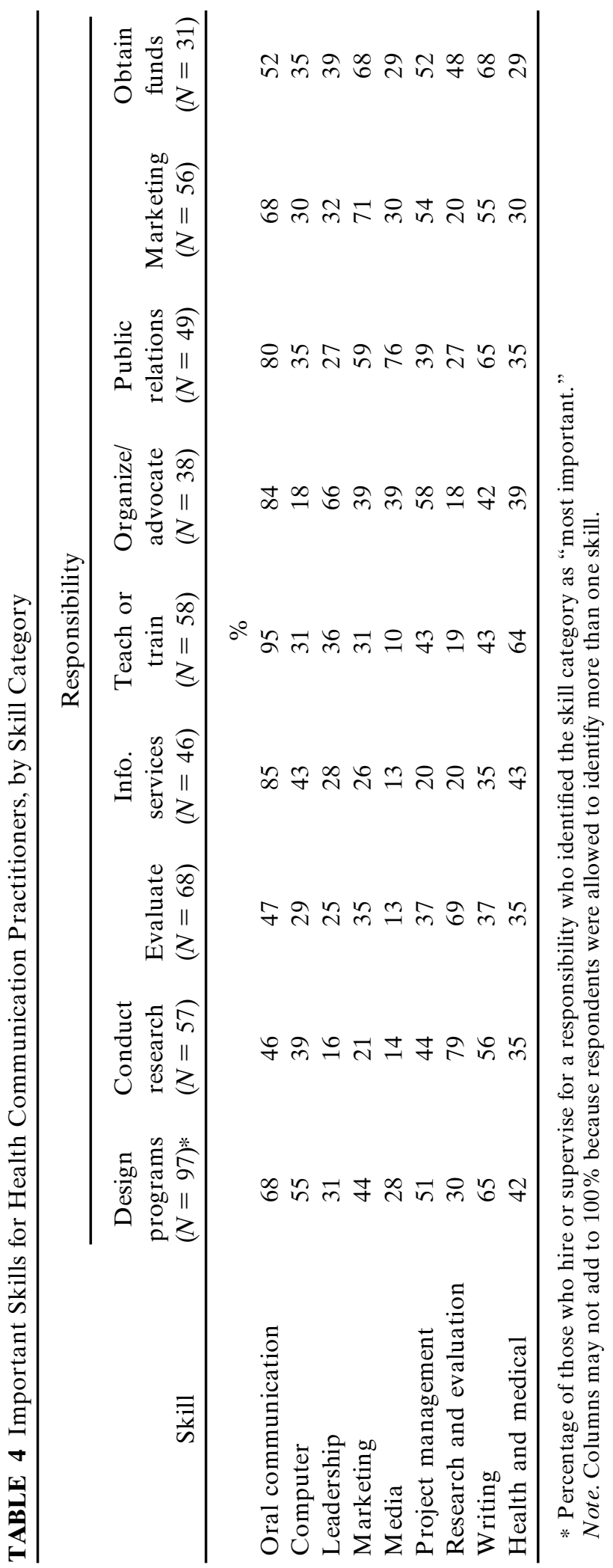


As a follow-up to ranking the importance of specialized knowledge, researchers asked respondents to specifically identify the area of health-related knowledge an employee performing this responsibility for them would need. Their open-ended responses were grouped into 14 categories representing general health content areas. Cancer, chronic disease, and infectious disease (particularly HIV/AIDS and STDs) were the most prevalent content areas mentioned by the respondents.

The study also explored specific skills employees would need to perform these responsibilities. To assess this, respondents were provided a list of skills that were divided into nine categories: oral communication, computer, leadership, marketing, media, project management, research and evaluation, writing, and health and medical (Appendix B), and were asked to designate skills or skill categories that they felt were most important in helping employees to accomplish a specified responsibility. ${ }^{2}$ Table 4 presents the percentage of respondents for each responsibility whose answer fell into a skill category. Oral communication skills were seen as important by at least $46 \%$ of respondents for each responsibility. The importance of writing was evident across categories, with at least $35 \%$ of respondents for each responsibility naming this skill. The importance of all skills varied, depending on the responsibility.

\section{Necessary Academic Training or Professional Experience}

Another issue addressed in the study was the level of academic training that respondents reported as necessary to perform the responsibilities. Responsibilities most respondents named as requiring only an undergraduate degree included health-related public relations ( $80 \%$ of 49 respondents) and administering health information consumer services (78\% of 46 respondents). Responsibilities most commonly cited by respondents as requiring graduate level training include fundraising (62\% of 31 respondents) and program research $(60 \%$ of 57 respondents). See Table 3.

Respondents were asked to name as many academic fields as they thought were appropriate for sufficient background preparation for each responsibility. Respondents consistently cited three fields as important to the performance of each health communication responsibility: communication, health education, and public health. Some other fields frequently identified by respondents as relevant to some responsibilities included journalism, marketing, nursing, and fields related to research methodology (Table 5). Interviewers purposely avoided using the term "health communication" when questioning respondents about appropriate fields of study so as not to bias the results and, in fact, health communication was generally not volunteered for most responsibilities. Percentages ranged from $0 \%$ for obtaining funding to $13 \%$ ( 6 of 46 respondents) for administering health information services.

The field of communication itself was commonly mentioned, ranking as at least the fifth most mentioned field for each responsibility. Among the responsibilities of evaluation, administering health information services, and health-related public relations, communication was the most mentioned field of study.

To gain further insight, we collapsed the academic fields of communication, health communication, mass communication, and speech communication into a "general communication studies" category. Overall, $62 \%$ of the study respondents

2 To avoid overemphasizing a category during analysis, multiple skills for the same category were counted as a single response. That is, if a respondent suggested both counseling and persuasive skills within oral communication, it was considered one response for the category oral communication.

Click here to access the Journal of Health Communication Online 


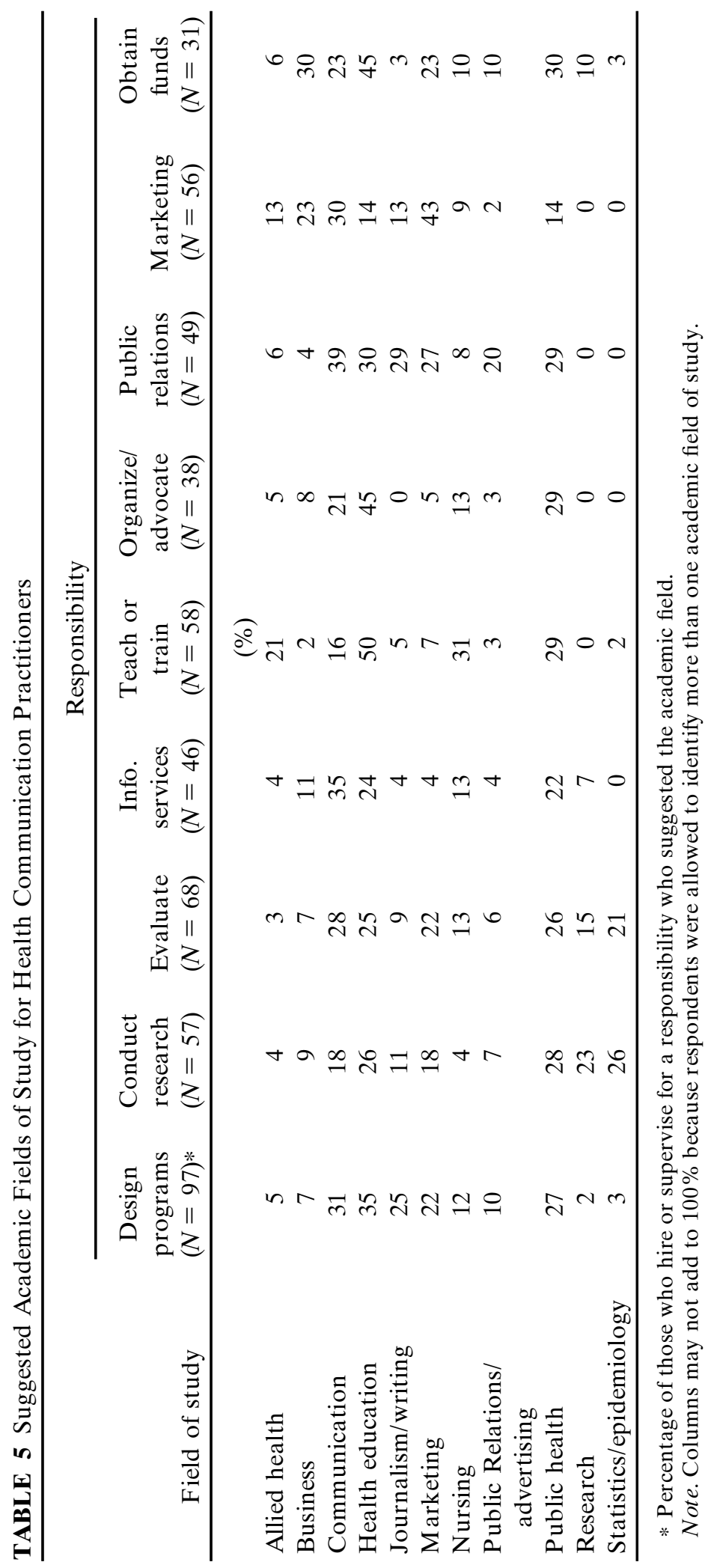


recommended a field within general communication studies for at least one of the nine health communication responsibilities, and this collapsed category was the most prevalent answer in all responsibilities except organizing coalitions/acting as an advocate, marketing, and obtaining funding.

Another component of the study addressed respondents' views of the level of job experience required for employees to perform health communication responsibilities. To gauge this, we developed four categories of experience and asked respondents to classify responsibilities using these categories (Table 3 ).

Generally, the respondents deemed 1 to 5 years or 6 to 10 years of experience necessary to perform most health communication job responsibilities. Entry level experience was generally not desired.

\section{Discussion}

This study can be viewed as a first step toward clearly identifying current issues affecting health communication employment in the present and near future. To do so, it sought to answer three overarching questions as to the employment outlook of the health communication field, knowledge and skills health practitioners should possess, and necessary academic training and academic experience. What follows is a discussion of the study results and the implications these findings might have on those seeking employment in health communication.

\section{Limitations}

This study has attempted to answer some basic questions about the health communication job market and the responsibilities required of health communication. We believe the results provide a strong basis for further research on the topic and for efforts to advance the field. There are, however, some limitations to this study that should be considered. First, because the sample was prospective and the number of respondents small compared with the total possible number of employers of health communication practitioners, the results here cannot be generalized to the field of health communication as a whole. Second, the number of respondents who hire or supervise employees who design programs, campaigns, or materials may be slightly inflated due to (1) a liberal interpretation of the responsibility, (2) the introduction of a bias for this responsibility through the participant screening process, or (3) overselection by respondents because this responsibility was always the first one discussed in the interview. With regard to the anticipated need for new staff, this answer considered only the perceived need of the respondent and did not consider industry trends, such as downsizing or hiring freezes. We recorded measures concerning specialized knowledge in a health-related field, professional experience, and academic training separately but were unable to determine the relative impact of one measure on the other. It is possible that this sample did not capture all health communication practitioners in the organization, but only those under the immediate supervision of the respondents. Last, the study did not capture the total number of health communication staff at each organization nor the extent to which employees perform multiple responsibilities.

\section{The Employment Outlook for Health Communication Practitioners}

The results regarding an anticipated need for new or more staff in every core responsibility indicate that the field of health communication will experience a mod- 
erate expansion. Not only will employees hire more people for responsibilities already being performed, organizations will be adding new responsibilities to the health communication duties for their office or department. The need for more people to fulfill more responsibilities is good news for health communication practitioners entering the job market. Not only is it likely that more jobs will be available in the new millenium, but job seekers can also look forward to choosing between opportunities in many different areas of responsibility.

Another observation indicating a positive employment outlook is the diversity of the organizations represented in the study sample. The fact that respondents were found in organizations that varied widely in size, type, and geographic location indicates that organizations of all types have been effective at adapting health communication to their needs and missions.

\section{Skills and Knowledge a Competent Health Communication Practitioner Should Possess}

Not surprisingly, the great majority of respondents considered specialized knowledge in a health content area somewhat important or very important, indicating that employees are expected to have at least a general familiarity with relevant health issues. Among these respondents, knowledge of cancer, chronic disease, and infectious disease (particularly HIV/AIDS) were noted as important health content areas; however, this may reflect the project work of the individual organizations represented in this study rather than the field as a whole. Future studies may explore what knowledge in particular aspects of these health content areas (e.g., epidemiology of a disease; the knowledge, attitude, and practices of affected populations; or legal and political issues) is important.

It is interesting to note that a significant number of respondents considered specialized knowledge in a health content area only somewhat important, suggesting that employees value other specialized knowledge in addition to knowledge of a health content area. Further research should explore what other specialized knowledge would be important to employers. At the very least, this finding indicates that health communicators must be able to transfer skills from different disciplines and apply them to health communication.

Our results indicate that all health communication practitioners should have good oral communication skills and writing skills. But the findings suggest that it is also necessary to possess a variety of additional skills, even if the practitioner's job encompasses only one of the core responsibilities. For example, oral communication skills are strongly desired in those who administer health information services, but those people are also expected to be competent in computer skills, writing skills, and health and medical skills. Advice for those new to the field is to develop skills that are highly desirable across several responsibilities, such as computers, marketing, project management, research and evaluation, and health and medical skills.

\section{Necessary Academic Training or Professional Experience}

Because results indicate a low demand for entry-level practitioners and a high demand for those with 1 to 10 years of experience, those wishing to enter the field of health communication should strongly consider internships or volunteer work before applying for permanent positions. By spending a relatively short period of time in an unpaid or temporary health communication position gaining experience in at least some of the health communication responsibilities, a person can greatly increase his or her hiring potential. 
Results suggest employees will hire health communication practitioners with only an undergraduate degree, and that some responsibilities, such as public relations and health information services, do not require an advanced degree in order to perform job duties well. However, for several responsibilities, such as program evaluation, conducting research, and obtaining funding, there was marked emphasis on an advanced degree.

Although very few respondents suggested health communication as an academic field prospective employees should pursue, there is a general recognition among these respondents of the need for people with formal academic training in a communication-related field. A major challenge for health communication practitioners and organizations such as the International Communication Association and the National Communication Association is to help employers make the connection between health communication as an academic field and health communication responsibilities. Likewise, those graduating in health communication need to learn how to market health communication skills to employers unfamiliar with the unique merits of a health communication concentration or degree.

\section{References}

Association of Schools of Public Health. (1999, July). Major areas of study offered by each school [On-line]. Available: http://www.asph.org/majarea.htm

HealthCOMM. (1999, July). Schools with health communication programs [On-line]. Available: http ://davinci.sla.purdue.edu/healthcomm/schools-AM .html

Northouse, P. G., \& Northouse, L. L. (1985). Health communication: A handbook for health professionals. Englewood Cliffs, NJ : Prentice-Hall.

Maibach, E., Parrott, R. L., Long, D. M., \& Salmon, C. T. (1994). Competencies for the health communication specialist of the 21st century. American Behavioural Scientist, 38 (2), 351360.

Ratzan, S. C., Stearns, N. S., Payne, J. G., Amato, P. P., Liebergott, J. W., \& Madoff, M. A. (1994). Education for the health communication professional: A collaborative curricular partnership. American Behavioral Scientist, 38 (2), 361-380.

Roper, W. L. (1993). Health communication takes on new dimensions at CDC. Public Health Reports, 108 (2), 178-183.

Stearns, N., Ratzan, S., Hyde, J., Newell, P., Joyce, M., \& Freeman, S. (1996, July). Crafting a graduate program in health communication: Insights from employers, practitioners, and academicians. Paper presented at the International Conference on Teaching about Communication in Medicine, Oxford, England. 


\section{Appendix A: Organization Types 3,4}

- Government agencies (27): Federal government agencies (5), state health departments (13), local health departments (9). (Small states had fewer than 1.7 million residents, medium states had between 1.7 and 4.8 million, and large state had over 4.8 million. Medium cities had more than 100,000 residents but fewer than 200,000 and large cities had more than 200,000.)

- Health care industry (25). General medical and surgical hospitals (8), offices and clinics of doctors of medicine (5), accident and health insurance (4), hospital and medical service plans (4), and pharmaceutical preparations (4). (Only medium and large organizations were sampled. Medium organizations had a minimum of 75 employees and a maximum of 1,000 employees. Large organizations had more than 1,000 employees.)

- Nonprofit organizations (nongovernmental) (26). Advocacy, charitable, and voluntary organizations (9); professional membership organizations (9); and colleges, universities, and professional schools (8): (Colleges with enrollments of fewer than 5,000 students were classified as small, those with more than 5,000 and less than 10,000 as medium, and those with enrollments in excess of 10,000 as large. For others, the size criteria were small, those with 25 or fewer employees; medium, those with more than 25 and less than 100 employees; and large, those with 100 or more employees.)

- For-profit organizations (not health care) (26). Advertising agencies (10); commercial economic, sociological, and educational research (9); and noncommercial research organizations (7): (Those with 25 or fewer employees were classified as small, those with more than 25 and less than 50 were medium, and those with 50 or more employees were large.

${ }^{3}$ Dun \& Bradstreet lists firms by Standard Industrial Classification (SIC). The SIC system was developed by the federal Office of Management and Budget to classify establishments to aid in analysis of the economy. Establishments are divided into letter divisions (such as Division A-agriculture), two-digit major groups (such as Major Group 01- agricultural products- crops), three-digit industry groups (such as Industry Group 011- cash grains), and four-digit industry numbers (such as Industry Number 0111wheat). Each of the divisions, major groups, industry groups, and industry numbers is explained in detail in the SIC manual published by the Office of Management and Budget.

${ }^{4}$ Within each organization type, the relevant size distribution was examined to determine the cutoffs for small, medium, and large. 


\section{Appendix B: List of Skills Sent to Respondents}

\section{List of Skills for Health Communication Practitioners}

Below is a reference list of some skills that health communication practitioners might use in their work. Note that it is not complete or exhaustive, but it might be a useful starting point for the section of the interview where we ask about skills. If you have a chance, you may want to peruse the list before the interview.

\author{
Oral communication skills \\ Counseling \\ Persuasive skills \\ Interviewing skills \\ Public speaking and presentation \\ Intercultural communication
}

\section{Computer skills}

Ability to use at least one word processing package

Graphics skills

Spreadsheet skills

Ability to use at least one statistical package Ability to use advanced telecommunications (e.g., databases, Internet)

\section{Leadership skills}

Consensus building and collaboration

Conflict managemen $t$

Problem solving

Decision making

Organizational skills

\section{Marketing skills}

Fundraising

Promotional skills

Program planning and design

Cost-benefit analysis

Audience analysis

\section{Media skills}

Media relations

Using entertainment programming as a commercial tool

Media advocacy

\section{Project management skills}

Contract and budget management

Strategic planning

Ability to impose a process on a confusing situation

Project planning and design

Personnel managemen $\mathrm{t}$

Team building

\section{Research and evaluation skills}

Questionnaire design

Design and analysis of quantitative studies

Design and analysis of qualitative studies

Sampling design

Analysis of secondary data

Focus group facilitation

\section{Writing skills \\ Academic writing/editing \\ Technical writing/editing \\ Journalistic writing/editing \\ Copywriting/editing}

\section{Health and medical skills}

Ability to apply knowledge of epidemiology Ability to apply health behavior theories Ability to apply knowledge of public health Ability to apply knowledge of health care delivery systems

\section{Other}

\section{(1)}

